\title{
Corrupción Administrativa y la obtención de Evidencia o Medios de prueba
}

\section{Administrative Corruption and obtaining Evidence or Means of proof}

Dora Patricia Soto Martinez

Universidad de San Carlos de Guatemala

dopasomar05@gmail.com

https://orcid.org/0000-0002-3435-3168

Recibido: $14 / 07 / 2021$

Aceptado: 01/09/2021

\section{Resumen}

\section{Referencia del artículo}

Soto Martinez, D. P. (2021). Corrupción Administrativa y la obtención de Evidencia o Medios de prueba. Revista Diversidad Científica, 1(1), 185-193.

\section{DOI: https://doi.org/10.36314/diversidad.v1i1.20}

OBJETIVO: identificar los medios de prueba valorados e inclusivos en un proceso de investigación. MÉTODO: en el proceso de preparación del documento se estableció los requisitos que se consideran para aceptar un medio de prueba valorado. RESULTADOS: la corrupción administrativa es un proceso complejo de desarticular, donde intervienen agentes políticos y sociales con intenciones de concentrar el poder para su propio beneficio y de sus familiares o amigos por ellos se estima que todo elemento de prueba, para ser valorado, debe haber sido obtenido por un procedimiento permitido y previo a la incorporación del proceso de investigación. CONCLUSIÓN: Ios medios de prueba aportados en cualquier proceso de investigación deben ser suficientes, competentes y objetivos, deben obtenerse de acuerdo con los procedimientos permitidos, y evitar la inclusión de elementos probatorios prohibidos y confusos.

Palabras clave: corrupción administrativa, medio de prueba, información pública 


\begin{abstract}
OBJECTIVE: to identify the means of proof that are valued and inclusive in an investigation process. METHOD: in the process of preparing the document, the requirements that are considered to accept a valued test medium were established. RESULTS: administrative corruption is a complex process of dismantling, where political and social agents intervene with the intention of concentrating power for their own benefit and that of their relatives or friends, it is estimated that all evidence, to be assessed, must have been obtained by a permitted procedure and prior to the incorporation of the investigation process. CONCLUSION: The evidence provided in any investigation process must be sufficient, competent and objective, must be obtained in accordance with the permitted procedures, and avoid the inclusion of prohibited and confusing evidence.
\end{abstract}

Keywords: administrative corruption, means of proof, public information 


\section{Introducción}

La corrupción en la administración pública ha estado presente como una constante en el ejercicio del poder de los gobiernos, debilitando la gobernabilidad del país, en complicidad con actores privados, estructurando y afianzando un sistema de gobierno precario para una mayoría y en beneficio propio (ICEFI, OXFAM, 2015). En el ámbito financiero, la corrupción se nutre de la falta de transparencia en las decisiones, operaciones y procedimientos y por una responsabilidad deficiente (Auditoría Superior de la Federación -ASF-, 2012). La corrupción administrativa según Estrada (2013) afecta principalmente a los burócratas que forman parte de la administración pública, además funcionarios públicos, legisladores o administradores que controlan actividades y procedimientos y tienen injerencia en la toma de decisiones (Rowland, 1998) a través de actos corruptos que se comenten de acuerdo con las reglas y cuando las operaciones se desarrollan en contra de las reglas.

En referencia a lo anterior y dentro del proceso de las evaluaciones que realiza la entidad encargada del régimen de control y fiscalización de los ingresos, egresos y en general de todo interés hacendario de los organismos del Estado, municipios, entidades descentralizadas y autónomas (Constitución Política (Const). Art. 232. 17 de noviembre de 1993). Tiene la facultad para que durante el proceso de revisión y previo a emitir su informe de auditoría las entidades sujetas a fiscalización proporcionen toda información, documentos, libros, mensajes electrónicos, documentos digitales, inclusive, información contable que considere relevante, de acuerdo a su mandato y normativa. (LOCGC. Art. 7. 5 de junio de 2002)

Los informes de auditoría que emita la Entidad Fiscalizadora Superior -EFS- tienen plena validez y constituyen medios de prueba en juicio y fuera de él (LOCGC. Art. 28. 5 de junio de 2002), por ello los auditores gubernamentales preparan y ejecutan procedimientos de auditoría que permiten obtener información verificable, competente y oportuna, como evidencia para sustentar el informe de auditoría (ISSAI.GT 100, 2017, pp. 22-23).

Entre los medios de prueba abordados se encuentran: la prueba pericial o pericia, la prueba testimonial, la prueba documental, y la prueba de informes. Se estima que todo elemento de prueba, para ser valorado, debe haber sido obtenido por un procedimiento permitido e incorporado al proceso de investigación. (Código Procesal Penal, Decreto número 51-92 (CPP). Art. 186. 28 de septiembre de 1992) En ese sentido, surge la interrogante ¿Es importante el aporte de evidencia o medios de prueba en actos relacionados con la corrupción administrativa? cuya respuesta formara parte de la conclusión de este documento. 


\section{Contenido}

\section{Corrupción administrativa y la obtención de evidencia o medios} de prueba

Corrupción administrativa es un proceso complejo de desarticular, donde intervienen agentes políticos y sociales con intenciones de concentrar el poder para su propio beneficio y de sus familiares o amigos, conscientes de que acciones ilícitas o ilegítimas, sancionadas penalmente o no, afectan los intereses sociales y causan detrimento al estado (Castro-Martínez, et al., 2019).

Medio de prueba es el procedimiento establecido por ley tendiente a lograr el ingreso de elementos de prueba en el proceso. Houed (2007) citando a Florián, señala que la prueba presentada el momento justo es cuando manifiesta su mayor eficiencia, y, que por su intermedio el objeto de prueba se coloca al alcance de la parte interesada. (p. 26) Existe en el proceso penal una gran cantidad de medios de prueba que permiten afirmar que todo puede ser probado, por lo que resulta común que las legislaciones regulen el momento y calidad de la prueba, respetando los derechos de las partes involucradas (p. 25).

El CPP señala la objetividad de la prueba exceptuando lo que la ley penal disponga, que el Ministerio Público y los tribunales son quienes procuraran e indagan la verdad mediante los medios de prueba permitidos que faciliten probar los hechos y circunstancias de interés (Arts. 181-182. 28 de septiembre de 1992).

\section{La Prueba pericial o Pericia}

Siguiendo a Houed (2007) la prueba pericial se basa en un dictamen de especialistas, que cumpla y sea consentida como elemento de prueba valorada (p. 33).

\section{La Prueba o declaración testimonial}

Refiere Houed (2007) que esta prueba se basa en la exposición que realiza una persona física de lo que conoce acerca de los hechos que forman parte de una investigación. Existen aspectos o reglas de suma importancia que de acuerdo con Houed deben considerarse para dar por aceptada o admisible la prueba testimonial, siendo los siguientes: capacidad de rendir declaración; posibles razones de incompatibilidad del declarante; inhabilitación para declarar; facultad de abstención, 
secreto profesional y parentesco; obligación de comparecer; ofrecimiento; momento para recibir la declaración. En ese sentido, la tarea valorativa de este medio de prueba depende de la sana critica racional (pp. 34-38).

El CPP en artículo 28, agrega que una declaración implica exponer la verdad de cuanto se supiere y le fuere preguntado sobre el objeto de la investigación; el de no ocultar hechos, circunstancias o circunstancias, y artículo 211 que se investigará por los medios de que se disponga sobre la idoneidad del testigo; su identidad, relaciones con las partes, clase de vida y cuanto pueda dar información al respecto.

\section{La Prueba documental o documento}

Según D’Albora citado en Houed (2007) el documento es la concreción material de un pensamiento que abarca, signos, contraseñas, escritos anónimos, informes distintivos, emblemas, condecoraciones, etc., asimismo, el producto de ciertos mecanismos registradores tales como: máquinas controladoras, aparatos fotográficos, filmadoras, etc.; podrá obtenerse ya sea de ofrecimiento por las partes, por la vía coactiva o secuestro. (pp. 49-50) La orden de secuestro será extendida por juez competente según corresponda (CPP. Art. 200. 28 de septiembre de 1992).

En este tipo de prueba se necesita la seguridad que su contenido es lo que pretendía realmente dar a conocer su emisor y si lo que menciona es verdadero, para estos casos es viable una declaración jurada. Para el caso de los documentos públicos, por sí solos son constitutivos de prueba y gozan de plena fe (Houed, 2007, pp. 50-51).

El ente fiscalizador de la administración pública, durante el curso de las inspecciones o proceso de revisión puede obtener documentos, extractos y libros (copias físicas), mensajes electrónicos, documentos digitales, inclusive, información contable, de acuerdo a su mandato y normativa (LOCGC. Art. 7.5 de junio de 2002).

En el año 2008, fue promulgada la Ley de Acceso a la Información Pública, que garantiza el derecho y acceso libre a la información, documentos y actos de la administración pública. Sin embargo, deja como límites del derecho al acceso: a) lo que establece la Constitución Política de la República de Guatemala en artículo 24; y b) toda información que por leyes específicas sea clasificada como confidencial inclusive la derivada de convenios o tratados internacionales (LAIP. Arts. 21-23. 22 de octubre de 2008). 


\section{La Prueba de los informes}

Este medio de prueba es una refutación escrita, emitida por un ente experto en la materia, de carácter individual o jurídico, a petición judicial o del ámbito de competencia de quien lo emite, sobre situaciones preexistentes o presunciones documentadas. Se exceptúan los informes técnicos de la policía; los informes sujetos a observaciones en el acto por peritos. Importante tomar en cuenta que los informes para ser valorados como tal, las entidades o profesionales que los emitan deben gozar de certeza jurídica, idoneidad, prestigio y confianza (Houed, 2007, p. 51).

En lo que concierne a los informes de auditoría elaborados por la EFS, como los documentos y papeles de trabajo que se generen durante el desarrollo o proceso de la actividad de fiscalización, serán utilizados como evidencia. En ese sentido, el informe de auditoría tendrá plena validez y constituye medios de prueba en juicio y fuera de él. (LOCGC. Art. 28. 5 de junio de 2002) Los auditores gubernamentales para respaldar los hallazgos revelados deberán preparar y ejecutar procedimientos que permitan obtener información verificable, competente y oportuna, para sustentar el informe de auditoría y que este sea permitido como elemento de convicción (ISSAI.GT 100, 2017, pp. 22-23).

\section{Prueba inadmisible}

Especialmente es inaceptable una prueba, cuando los elementos que la representan son cuando se han obtenido a través de estrategias o procedimientos prohibidos o de forma mal intencionada, el código procesal penal establece que la tortura, ingresar al domicilio o residencia de una persona individual o jurídica y obtener documentos, bienes, colocar medios para interceptar la comunicación sin debida autorización (CPP. Art. 183. 28 de septiembre de 1992).

\section{Conclusiones}

Tomando de base las percepciones de la evidencia o medios de prueba expuestos en este documento para dar respuesta a la interrogante planteada al inicio con relación a si ¿Es importante el aporte de evidencia o medios de prueba en actos relacionados con la corrupción administrativa? se puede asentir que: el aporte de los medios de prueba deben ser suficientes, competentes y objetivos; deben ser obtenidos de acuerdo con los procedimientos permitidos e incorporados al proceso de investigación y análisis; evitar la inclusión de elementos probatorios obtenidos 
por medios prohibidos y confusos; las averiguaciones y revisiones previas, deben garantizar que los medios de prueba no desaparezcan o se pierdan durante el proceso y sean valorados conforme a sana crítica razonada.

\section{Declaración}

El estudio se realizó de acuerdo a las directrices del Código de Ética y Buenas Prácticas COPE, con las autorizaciones correspondientes.

\section{Conflicto de intereses}

La autora declara no tener ningún conflicto de intereses.

\section{Referencias}

Auditoría Superior de la Federación, México. (2012). Compilación técnica Corrupción, ética y fiscalización.

Castro-Martínez, J., Riera, C., y Machado, I. (2019). La corrupción administrativa: Un acercamiento a la definición. https://www.medigraphic.com/pdfs/infodir/ifd-2019/ ifd1928m.pdf

Congreso de la República de Guatemala. Decreto Número 51-92. (28 de septiembre de 1992). Código Procesal Penal. http://ww2.oj.gob.gt/es/QueEsOJ/Estructu$\mathrm{raOJ} /$ UnidadesAdministrativas/CentroAnalisisDocumentacionJudicial/pdfs/Codigos/CodigoProcesalPenal_CENADOJ.pdf

Congreso de la República de Guatemala. Decreto Número 31-2002. (5 de junio de 2002). Ley Orgánica de la Contraloría General de Cuentas. https://www.contraloria.gob.gt/wp-content/uploads/2018/02/2-LEY-ORGANICA-DE-LA-CONTRALORIA-GENERAL-DE-CUENTAS-Reformado-31-2002.pdf

Congreso de la República de Guatemala. Decreto Número 57-2008. (22 de octubre de 2008). Ley de Acceso a la Información Pública. https://www.contraloria.gob.gt/ 
wp-content/uploads/2018/02/10-LEY-DE-ACCESO-A-LA-INFORMACION-PUBLICA-DECRETO-57-2008.pdf

Constitución Política de la República de Guatemala. Acuerdo Legislativo No. 1893. (17 de noviembre de 1993). https://www.contraloria.gob.gt/wp-content/ uploads/2018/02/1-CONSTITUCION-POLITICA-1985.pdf

Contraloría General de Cuentas. (2017). Normas Internacionales de las Entidades Fiscalizadoras Superiores Adaptadas a Guatemala -ISSAI.GT- 100. https:// www.contraloria.gob.gt/wp-content/uploads/2017/12/ISSAI.GT-100.pdf

Estrada, J. (2013). La corrupción administrativa en México. http://www.scielo.org.mx/ scielo.php?script=sci_arttext\&pid=S1870-23332013000200007

Instituto Centroamericano de Estudios Fiscales ICEFI y OXFAM Guatemala. (2015). La corrupción sus caminos, su impacto en la sociedad y una agenda para su eliminación. Informe de Investigación de OXFAM.

Houed, M. (2007). La prueba y su valoración en el proceso penal. https://www.sijufor. org/uploads/1/2/0/5/120589378/03-la-prueba-y-su-valoracion-1-1.pd

\section{Sobre la autora}

\section{Dora Patricia Soto Martinez}

Es Licenciada en Contaduría Pública y Auditoría (URL), Maestra en Administración Financiera (USAC). Labora en Contraloría General de Cuentas, experiencia de 12 años en fiscalización a entidades descentralizadas, de gobierno central y consejos departamentales de desarrollo. Estudiante del Doctorado en Ciencias Económicas con Especialidad en Administración Financiera, Universidad de San Carlos de Guatemala. 
Copyright (c) Dora Patricia Soto Martinez

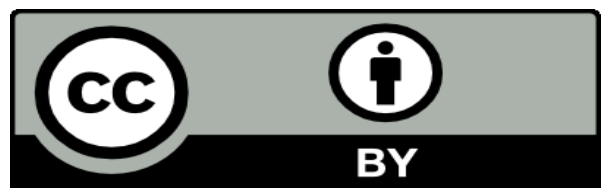

Este texto está protegido por una licencia CreativeCommons 4.0.

Usted es libre para compartir, copiar y redistribuir el material en cualquier medio o formato y adaptar el documento, remezclar, transformar y crear a partir del material para cualquier propósito, incluso comercialmente, siempre que cumpla la condición de atribución: usted debe reconocer el crédito de una obra de manera adecuada, proporcionar un enlace a la licencia, e indicar si se han realizado cambios. Puede hacerlo en cualquier forma razonable, pero no de forma tal que sugiera que tiene el apoyo del licenciante o lo recibe por el uso que hace. 